\section{Cureus}

Received 04/12/2019

Review began 04/14/2019

Review ended 04/15/2019

Published 04/24/2019

\section{(c) Copyright 2019}

Shahid et al. This is an open access article distributed under the terms of the Creative Commons Attribution License CC-BY 3.0., which permits unrestricted use, distribution, and reproduction in any medium, provided the original author and source are credited.

\title{
Refractory Sweet Syndrome Treated with Anakinra
}

\author{
Zainab Shahid $^{1}$, Ricci Kalayanamitra ${ }^{2}$, Ravi Patel ${ }^{3}$, Andrew Groff ${ }^{3}$, Rohit Jain ${ }^{3}$ \\ 1. Internal Medicine, Lake Erie College of Osteopathic Medicine, Erie, USA 2. Emergency Medicine, Penn \\ State Health Milton S. Hershey Medical Center, Hershey, USA 3. Internal Medicine, Penn State Health \\ Milton S. Hershey Medical Center, Hershey, USA
}

$\square$ Corresponding author: Zainab Shahid, zshahid44251@med.lecom.edu Disclosures can be found in Additional Information at the end of the article

\section{Abstract}

Sweet syndrome, otherwise known as acute febrile neutrophilic dermatosis, is an uncommon disorder characterized by the abrupt onset of painful cutaneous lesions, often with fever and leukocytosis, in patients with underlying infection, malignancy, pregnancy, or drug exposure. We present a case of a young female with long-standing Sweet syndrome refractory to standard treatments and several immunomodulators whose symptoms were ultimately controlled with anakinra.

Categories: Dermatology, Internal Medicine, Rheumatology

Keywords: sweet syndrome, acute febrile neutrophilic dermatosis, anakinra, chronic, refractory, recalcitrant

\section{Introduction}

Sweet syndrome was first reported in 1964 in the British Journal of Dermatology by Dr. Robert Douglas Sweet, who described eight women with skin eruptions, fever, and neutrophilic leukocytosis [1]. Sweet syndrome has since been associated with a range of disorders and is currently categorized into three subtypes based on etiology, namely as classical Sweet syndrome, malignancy-associated Sweet syndrome, and drug-induced Sweet syndrome. The first-line treatment for this condition is high-dose systemic corticosteroid therapy. Commonly used alternative medications include colchicine, dapsone, and potassium iodide [2]. There is a dearth of literature on cases of Sweet syndrome refractory to standard treatment, and even fewer reports of Sweet syndrome treated with anakinra [2-14].

\section{Case Presentation}

A 19-year-old female with a past medical history significant for long-standing Sweet syndrome requiring multiple emergency department visits presented to the emergency department with generalized muscle and joint pain and a diffuse outbreak of papules and vesicles. Her condition had been refractory to corticosteroids, colchicine, dapsone, adalimumab, abatacept, infliximab, etanercept, azathioprine, leflunomide, lenalidomide, and methotrexate, and was being managed with tocilizumab. The patient's condition was consistent with an acute exacerbation of Sweet syndrome and she was treated and discharged on a $40 \mathrm{mg}$ prednisone taper.

Two days after this visit, the patient returned to the emergency department with worsening muscle and joint pain and a new eruption of diffuse skin lesions. Vital signs revealed a temperature of $36.7^{\circ} \mathrm{C}$, pulse of 104 beats per minute, blood pressure of $139 / 90 \mathrm{mmHg}$, respiratory rate of 18 , and oxygen saturation of $99 \%$ on room air. Physical examination revealed 


\section{Cureus}

tender, erythematous, and ulcerating papules and pustules scattered over the trunk, bilateral upper and lower extremities, and face. Laboratory workup was notable for a leukocyte count of 16,800 cells $/ \mu \mathrm{L}$ in the setting of recent steroid use, platelet count of 411,000 platelets $/ \mu \mathrm{L}, \mathrm{c}-$ reactive protein of $1.15 \mathrm{mg} / \mathrm{L}$, and erythrocyte sedimentation rate of $37 \mathrm{~mm} / \mathrm{h}$.

The patient was admitted and started on $250 \mathrm{mg}$ of methylprednisolone twice per day and colchicine $0.6 \mathrm{mg}$ twice per day but continued to develop new lesions on her face, lower back, and tongue. Pain management was attempted with acetaminophen, gabapentin, tizanidine, duloxetine, and toradol, and ultimately the patient's pain was controlled with hydromorphone $4 \mathrm{mg}$ taken every three hours as needed. The patient was given $100 \mathrm{mg}$ of anakinra and her skin lesions began to improve. She was discharged with oral pain medications after a seven-day inpatient stay and followed up with outpatient rheumatology for continued treatment.

\section{Discussion}

Sweet syndrome is an uncommon disorder and therefore it is often missed on initial presentation. Specific diagnostic criteria have been established for each subtype of this syndrome (Tables 1-2). Classical Sweet syndrome represents the majority of cases and develops most commonly in individuals between the ages of 30 and 60 in the settings of inflammatory bowel disease, pregnancy, or a few weeks after an upper respiratory or gastrointestinal infection [2]. Malignancy-associated Sweet syndrome can occur before, after, or concurrently with either a solid tumor or hematologic malignancy. This subtype tends to affect older patients, with one study estimating the average age at diagnosis of 68 years old [15]. Druginduced Sweet syndrome usually develops a few weeks after initial drug exposure and is most commonly due to granulocyte-colony stimulating factor (G-CSF). All subtypes of this syndrome have a female predominance [2].

\section{Major criteria}

Abrupt onset of painful erythematous plaques or nodules

Histopathologic evidence of a dense neutrophilic infiltrate without evidence of leukocytoclastic vasculitis

\section{Minor criteria}

Pyrexia $>38 \mathrm{C}$

Association with underlying hematologic or visceral malignancy, inflammatory disease, or pregnancy OR preceded by an upper respiratory or gastrointestinal infection or vaccination

Excellent response to treatment with systemic corticosteroids or potassium iodide

Abnormal laboratory values at presentation (three of four); erythrocyte sedimentation rate $>20 \mathrm{~mm} / \mathrm{h}$; positive c-reactive protein; $>8,000$ leukocytes; $>70 \%$ neutrophils

\section{TABLE 1: Diagnostic criteria for classical and malignancy-associated Sweet syndrome}

The diagnosis of classical or malignancy-associated Sweet syndrome requires both of the major criteria and two of the four minor criteria to be met [2]. 


\section{Cureus}

\section{Major criteria}

Abrupt onset of painful erythematous plaques or nodules

Histopathologic evidence of a dense neutrophilic infiltrate without evidence of leukocytoclastic vasculitis

Pyrexia $>38 \mathrm{C}$

Temporal relationship between drug ingestion and clinical presentation OR temporally-related recurrence after oral challenge

Temporally related resolution of lesions after drug withdrawal or treatment with systemic corticosteroids

\section{TABLE 2: Diagnostic criteria for drug-induced Sweet syndrome}

The diagnosis of drug-induced Sweet syndrome requires all five criteria to be met [2].

The pathogenesis of this disorder is not well understood but is theorized to be at least partially due to cytokine dysregulation. G-CSF is believed to contribute to this disorder because it increases circulating neutrophils. In support of this, one study comparing patients with active and inactive Sweet syndrome revealed elevated production of G-CSF in patients with active Sweet syndrome [16]. In another study, interleukin-1, interleukin-2, and interferon-gamma were found to be elevated in patients with active Sweet syndrome [17]. These findings are supported by the efficacy of certain immunomodulatory drugs in cases of refractory Sweet syndrome and by the fact that interleukin-1 induces endothelial cell release of G-CSF [3-14,18].

Our patient's case is distinct from previous reports because she failed both standard corticosteroid and colchicine therapies, and failed trials of multiple immunomodulatory medications. Her symptoms were eventually controlled with anakinra, an interleukin-1 receptor antagonist, and this response further supports the likelihood of an interleukin-1 pathway in the pathogenesis of Sweet syndrome. It also opens the possibility that our patient's case represents an example of an interleukin-1 mediated variant of Sweet syndrome and that multiple variants of this syndrome may exist, especially because the patient's symptoms were refractory to the interleukin-6 receptor inhibitor tocilizumab. It is important that further research is conducted on Sweet syndrome in a large cohort of patients in order to determine the pathogenesis as well as investigate the possibility of multiple variants.

\section{Conclusions}

Sweet syndrome should be considered in patients presenting with an abrupt onset of a diffuse rash with possible fever and leukocytosis, especially in the settings of recent drug use, malignancy, inflammatory disorder, and recent infection. In addition, anakinra should be considered in patients whose symptoms are unresponsive to both standard treatments and immunomodulators because although the syndrome itself is not fatal, it is very painful and often requires opioid therapy for appropriate pain control.

\section{Additional Information}

\section{Disclosures}

Human subjects: Consent was obtained by all participants in this study. Conflicts of interest: In compliance with the ICMJE uniform disclosure form, all authors declare the following: 
Payment/services info: All authors have declared that no financial support was received from any organization for the submitted work. Financial relationships: All authors have declared that they have no financial relationships at present or within the previous three years with any organizations that might have an interest in the submitted work. Other relationships: All authors have declared that there are no other relationships or activities that could appear to have influenced the submitted work.

\section{References}

1. Sweet RB: An acute febrile neutrophilic dermatosis . Br J Dermatol. 1964, 76:349-356. 10.1111/j.1365-2133.1964.tb14541.x

2. Cohen PR: Sweet's syndrome - a comprehensive review of an acute febrile neutrophilic dermatosis. Orphanet J Rare Dis. 2007, 2:34. 10.1186/1750-1172-2-34

3. Delluc A, Limal N, Puéchal X, Francès C, Piette JC, Cacoub P: Efficacy of anakinra, an IL1 receptor antagonist, in refractory sweet syndrome. Ann Rheum Dis. 2008, 67:278-279. 10.1136/ard.2006.068254

4. Kluger N, Gil-Bistes D, Guillot B, Bessis D: Efficacy of anti-interleukin-1 receptor antagonist anakinra (kineret ${ }^{\circledR}$ ) in a case of refractory sweet's syndrome. Dermatology. 2011, 222:123127. $10.1159 / 000326112$

5. Passaro G, Cerrito L, Giovinale M, Marinaro A, Soriano A, Rigante D, Manna R: P03-019 anakinra for sweet syndrome treatment. Pediatr Rheumatol Online J. 2013, 11:217. Accessed: April 5, 2019: 10.1186/1546-0096-11-S1-A217

6. Agarwal A, Barrow W, Selim MA, Nicholas MW: Refractory subcutaneous sweet syndrome treated with adalimumab. JAMA Dermatol. 2016, 152:842-844. 10.1001/jamadermatol.2016.0503

7. Hashemi SM, Fazeli SA, Vahedi A, Golabchifard R: Rituximab for refractory subcutaneous sweet's syndrome in chronic lymphocytic leukemia: a case report. Mol Clin Oncol. 2016, 4:436-440. 10.3892/mco.2015.715

8. Fujii A, Mizutani Y, Hattori Y, Takahashi T, Ohnishi H, Yoshida S, Seishima M: Sweet's syndrome successfully treated with granulocyte and monocyte adsorption apheresis. Case Rep Dermatol. 2017, 9:13-18. 10.1159/000475878

9. Karamlou K, Gorn AH: Refractory sweet syndrome with autoimmune organizing pneumonia treated with monoclonal antibodies to tumor necrosis factor. J Clin Rheumatol. 2004, 10:331335. 10.1097/01.rhu.0000147053.60795.46

10. Andrés BM, Lozano VS, Melgarejo JFS: Sweet syndrome after treatment with vedolizumab in a patient with crohn's disease. Rev Esp Enferm Dig. 2018, 110:530.

10.17235/reed.2018.5603/2018

11. Browning CE, Dixon JE, Malone JC, Callen JP: Thalidomide in the treatment of recalcitrant sweet's syndrome associated with myelodysplasia. J Am Acad Dermatol. 2005, 53:135-138. 10.1016/j.jaad.2004.12.041

12. Watson IT, Haugh I, Gardner AR, Menter MA: Histiocytoid sweet syndrome successfully treated with etanercept. Proc (Bayl Univ Med Cent). 2018, 31:347-349.

10.1080/08998280.2018.1460132

13. Fellermann K, Rudolph B, Witthöft T, Herrlinger KR, Tronnier M, Ludwig D, Stange EF: Sweet syndrome and erythema nodosum in ulcerative colitis, refractory to steroids: successful treatment with tacrolimus. Med Klin (Munich). 2001, 96:105-108. 10.1007/PL00002176

14. Melboucy-Belkhir S, Brigant F, Khentache R, Bouketouche M, Garidi R, Brihaye B: Sweet syndrome successfully treated with ruxolitinib in JAK-2 positive myeloproliferative disorder. Int Arch Intern Med. 2017, 2:8. 10.23937/iaim-2017/1710008

15. Rochet NM, Chavan RN, Cappel MA, Wada DA, Gibson LE: Sweet syndrome: clinical presentation, associations, and response to treatment in 77 patients. J Am Acad Dermatol. 2013, 69:557-564. Accessed: April 5, 2019: 10.1016/j.jaad.2013.06.023

16. Kawakami T, Ohashi S, Kawa Y, Takahama H, Ito M, Soma Y, Mizoguchi M: Elevated serum granulocyte colony-stimulating factor levels in patients with active phase of sweet syndrome and patients with active behcet disease: implication in neutrophil apoptosis dysfunction. Arch Dermatol. 2004, 140:570-574. 10.1001/archderm.140.5.570

17. Giasuddin AS, El-Orfi AH, Ziu MM, El-Barnawi NY: Sweet's syndrome: is the pathogenesis 
Cureus

mediated by helper t cell type 1 cytokines?. J Am Acad Dermatol. 1998, 39:940-943. 10.1016/S0190-9622(98)70266-X

18. Broudy VC, Kaushansky K, Harlan JM, Adamson JW: Interleukin 1 stimulates human endothelial cells to produce granulocyte-macrophage colony-stimulating factor and granulocyte colony-stimulating factor. J Immunol. 1987, 139:464-468. 